\title{
Article \\ Mechanistic Modelling Identifies and Addresses the Risks of Empiric Concentration-Guided Sorafenib Dosing
}

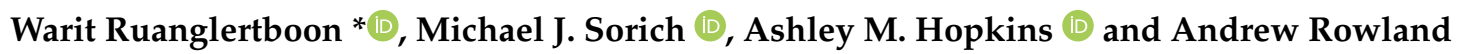 \\ College of Medicine and Public Health, Flinders University, Bedford Park, SA 5042, Australia; \\ michael.sorich@flinders.edu.au (M.J.S.); ashley.hopkins@flinders.edu.au (A.M.H.); \\ andrew.rowland@flinders.edu.au (A.R.) \\ * Correspondence: warit.ruanglertboon@flinders.edu.au
}

Citation: Ruanglertboon, W.; Sorich, M.J.; Hopkins, A.M.; Rowland, A. Mechanistic Modelling Identifies and Addresses the Risks of Empiric Concentration-Guided Sorafenib Dosing. Pharmaceuticals 2021, 14, 389. https://doi.org/10.3390/ph14050389

Academic Editors: Mary J. Meegan and Niamh M O’Boyle

Received: 11 March 2021

Accepted: 19 April 2021

Published: 21 April 2021

Publisher's Note: MDPI stays neutral with regard to jurisdictional claims in published maps and institutional affiliations.

Copyright: (C) 2021 by the authors Licensee MDPI, Basel, Switzerland. This article is an open access article distributed under the terms and conditions of the Creative Commons Attribution (CC BY) license (https:// creativecommons.org/licenses/by/ $4.0 /)$.

\begin{abstract}
The primary objective of this study is to evaluate the capacity of concentration-guided sorafenib dosing protocols to increase the proportion of patients that achieve a sorafenib maximal concentration $\left(C_{\max }\right)$ within the range 4.78 to $5.78 \mu \mathrm{g} / \mathrm{mL}$. A full physiologically based pharmacokinetic model was built and validated using Simcyp ${ }^{\circledR}$ (version 19.1). The model was used to simulate sorafenib exposure in 1000 Sim-Cancer subjects over 14 days. The capacity of concentration-guided sorafenib dose adjustment, with/without model-informed dose selection (MIDS), to achieve a sorafenib $C_{\max }$ within the range 4.78 to $5.78 \mu \mathrm{g} / \mathrm{mL}$ was evaluated in 500 Sim-Cancer subjects. A multivariable linear regression model incorporating hepatic cytochrome P450 (CYP) 3A4 abundance, albumin concentration, body mass index, body surface area, sex and weight provided robust prediction of steady-state sorafenib $C_{\max }\left(R^{2}=0.883 ; p<0.001\right)$. These covariates identified subjects at risk of failing to achieve a sorafenib $C_{\max } \geq 4.78 \mu \mathrm{g} / \mathrm{mL}$ with $95.0 \%$ specificity and $95.2 \%$ sensitivity. Concentration-guided sorafenib dosing with MIDS achieved a sorafenib $C_{\max }$ within the range 4.78 to $5.78 \mu \mathrm{g} / \mathrm{mL}$ for 38 of 52 patients who failed to achieve a $C_{\max } \geq 4.78 \mu \mathrm{g} / \mathrm{mL}$ with standard dosing. In a simulation setting, concentration-guided dosing with MIDS was the quickest and most effective approach to achieve a sorafenib $C_{\max }$ within a designated range.
\end{abstract}

Keywords: concentration-guided dosing; model informed dosing; physiologically based pharmacokinetics; sorafenib

\section{Introduction}

Sorafenib is an orally administered small molecule kinase inhibitor (KI) used in the treatment of advanced hepatocellular (HCC) and renal cell (RCC) carcinomas. Sorafenib is a potent inhibitor of multiple kinase receptors including the vascular endothelial growth factor receptor (VEGFR), endothelial growth factor (subtype 1, 2 and 3), platelet-derived growth factor-beta (PDGFR $\beta$ ) and fibroblast growth factor receptor 1 (FGFR1). Variability in sorafenib exposure between individuals and within an individual over time has been identified as a potential source of heterogeneity in treatment efficacy and tolerability [1,2]. The area under the plasma concentration curve (AUC) and maximal concentration $\left(\mathrm{C}_{\max }\right)$ for sorafenib following has been reported to vary more than $50 \%$ with standard $400 \mathrm{mg}$ dosing [3-5]. Variability in gastrointestinal absorption due to limited and $\mathrm{pH}$ dependent solubility has been proposed as a major source of variability in exposure [6], however concomitant proton pump inhibitor (PPI) use, which is reported to reduce KI absorption [7], has been demonstrated to have no impact on survival outcomes in HCC [8] and RCC [9,10] patients treated with sorafenib.

A sorafenib $C_{\max } \geq 4.78 \mu \mathrm{g} / \mathrm{mL}$ has been associated with superior overall survival in RCC and HCC patients, albeit with a higher incidence of hypertension, while a sorafenib $\mathrm{C}_{\max } \geq 5.78 \mu \mathrm{g} / \mathrm{mL}$ has been associated with an increased incidence of grade II toxicity, the most common of which is hand foot skin reactions [11,12]. While the evidence for these thresholds is derived from a single observational study in 52 individuals, these values 
have been cited as target concentrations in multiple reviews addressing individualised sorafenib dosing $[13,14]$. The dose escalation protocol that has been proposed for sorafenib to increase from $400 \mathrm{mg}$ to $600 \mathrm{mg}$ twice daily [15]. This approach is based on a sub-analysis of a phase II trial demonstrating a clinical benefit in patients who increased from $400 \mathrm{mg}$ to $600 \mathrm{mg}$ sorafenib twice daily following disease progression at the $400 \mathrm{mg}$ dose [16]. Notably the association of this dose escalation with sorafenib plasma concentration has not been evaluated.

The potential benefits of individualised KI dosing have gained interest in recent years [17-19] and a number of strategies are available to both inform initial dose selection and facilitate dose adaption [20]. Therapeutic drug monitoring (TDM) is an established method to facilitate concentration-guided dose adaption but requires significant clinical and analytical resources to quantify the drug of interest and establish a robust evidence base. To date, few cancer medicines have met the level of evidence required to implement TDM in a clinical setting [21-23].

Model-informed initial dose selection (MIDS), often underpinned by a population pharmacokinetic (pop-PK) or physiologically based pharmacokinetic (PBPK) model, has emerged as a strategy to assist initial dose selection either to complement or replace TDM [24-27]. PBPK modelling and simulation is an established tool in drug discovery and development, where it is used to predict factors affecting PK and support the design of clinical trials [28,29]. PBPK is a 'bottom-up' approach whereby the concentration-time profile of a drug is simulated based on physiochemical and in vitro data [30,31]. Novel clinical applications for PBPK have been proposed involving the prediction of clinical drug-drug interactions, identification of physiological covariates impacting drug exposure and informing initial dose selection [25,31-33].

The primary objective of this study is to evaluate the capacity of concentration-guided sorafenib dose adjustment, with and without MIDS, to increase the proportion of patients that achieve a sorafenib $C_{\max }$ within a concentration range of 4.78 to $5.78 \mu \mathrm{g} / \mathrm{mL}$. A full body PBPK model for sorafenib was first developed and validated, then used to identify physiological and molecular covariates associated with between subject variability in sorafenib exposure.

\section{Results}

\subsection{Verification of the Sorafenib PBPK Compound Model}

The accuracy of the sorafenib compound model was assessed in nineteen age and sex matched cohorts from single or multiple ascending dose (100 to $800 \mathrm{mg}$ ) trials. Mean simulated and observed AUC and $\mathrm{C}_{\max }$ values and the corresponding simulated/observed ratios are presented in Table S1 along with a summary of the verification trial characteristics (i.e., age range, sex, sample size and dose). The mean ( \pm standard deviation; SD) simulated/observed AUC and $C_{\max }$ ratios for the single-dose cohorts $(n=37)$ were $1.92( \pm 1.11)$ and $1.50( \pm 1.7)$, respectively. The mean $( \pm \mathrm{SD})$ simulated/observed AUC and $C_{\max }$ ratios for the multiple-dose (typically 14 days) cohorts $(n=14)$ were $1.50( \pm 0.72)$ and $1.17( \pm 0.63)$, respectively. Variability in model performance, indicated by large SD for parameter ratios, was driven by heterogeneity in observed parameters between trials. A representative sorafenib concentration-time profile depicting overlayed with the mean concentrationtime profile and 90\% confidence interval (CI) for the observed data is shown in Figure 1. The accuracy of the sorafenib compound model was considered acceptable on the basis that mean simulated parameters were within two-fold of the respective mean observed parameter and contained within the $90 \%$ CI for the observed parameter. Simulated Day 14 and Day 28 sorafenib $C_{\max }$ values were divided by 1.17 to account for simulation to observed MFE in multiple dose studies when evaluating the simulated parameters against the observed target $C_{\max }$ range. Results of sensitivity analyses performed to evaluate the impact of input parameters with measurement uncertainty $\left(\mathrm{C}_{\text {lint }}\right.$ for CYP3A4 and UGT1A9 pathways, fraction unbound, $\mathrm{B} / \mathrm{P}$ ratio and $\log \mathrm{P}$ ) on sorafenib kinetic parameters are shown in Figure S1. 


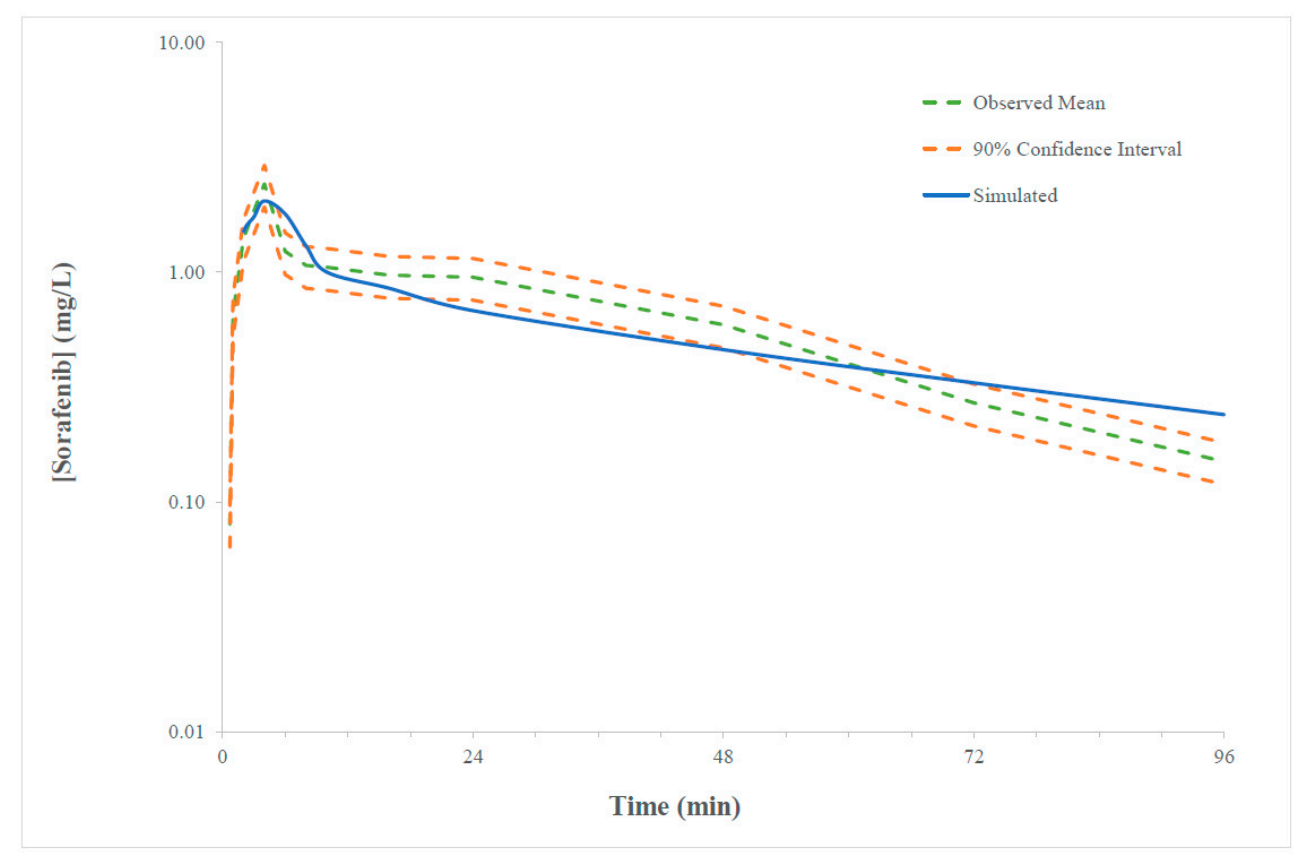

Figure 1. Representative overlay of simulated and observed (range) plasma concentration time curve of sorafenib (0-96 h) following $400 \mathrm{mg}$ twice a day dosing. Solid blue line represented the mean model predicted exposure, dashed green line represented the mean observed exposure and dashed orange represented minimal and maximal $90 \%$ confidence intervals for the observed data.

\subsection{Sorafenib Exposure in Cancer Patient}

The summary of the mean, $\mathrm{SD}$ and range of steady-state sorafenib AUC and $\mathrm{C}_{\max }$ parameters defining exposure in 1000 virtual cancer patients is presented in Table S2. Consistent with the reported clinical trial data [4,5,34], the simulation revealed variability of greater than an order of magnitude in sorafenib exposure; the steady state AUC ranged from 22.7 to $270 \mathrm{mg} / \mathrm{L} \cdot \mathrm{h}$ (mean $99.2 \mathrm{mg} / \mathrm{L} \cdot \mathrm{h}$ ), while $C_{\max }$ ranged from 2.3 to $23.2 \mu \mathrm{g} / \mathrm{mL}$ (mean $8.9 \mu \mathrm{g} / \mathrm{mL}$ ).

\subsection{Physiological and Molecular Characteristics Driving Variability in Sorafenib Exposure}

Univariate logistic regression analysis evaluated correlations between physiological and molecular characteristics and sorafenib steady state $C_{\max }$ threshold at $>4.78 \mathrm{mg} / \mathrm{L}$ (Table S3) in a cohort of 1000 Sim-Cancer subjects. Statistical analysis of multivariable linear regression with stepwise inclusion of parameters revealed the primary covariates driving variability in sorafenib AUC were hepatic CYP3A4 abundance, albumin concentration, body mass index (BMI), body surface area (BSA), sex and weight (Figure 2).

A summary of the performance characteristics for the multivariable linear regression model is shown in Table 1. The covariate most strongly associated with variability in sorafenib AUC was hepatic CYP3A4 abundance, inclusion of albumin concentration and BMI resulted in substantial improvement in multivariable model fit. Stepwise inclusion of additional the covariates BSA, sex and weight resulted in minor improvements in model performance $\left(R^{2}\right.$ change $\left.\leq 0.010\right)$. No other covariate met the stepwise inclusion criteria (probability of $\mathrm{F}$ to enter $\leq 0.05$ ). These parameters formed the basis of the MIDS. The AUC of the ROC for the MIDS predicted steady state AUC was 0.991 (Figure 3). Sixty-three subjects (6.3\%) from the Sim-Cancer cohort failed to achieve a Day $14 \mathrm{C}_{\max }>4.78 \mu \mathrm{g} / \mathrm{mL}$. MIDS predicted individuals that failed to achieve a therapeutic sorafenib $C_{\max }$ with $95.2 \%$ sensitivity (60/63 sub-therapeutic individuals) and $95.0 \%$ specificity (809/937 therapeutic individuals) (Table 2, Figure 3). Shown in Figure S2, differences in albumin concentration between participants were associated with changes in $\mathrm{f}_{\mathrm{u}}$. 


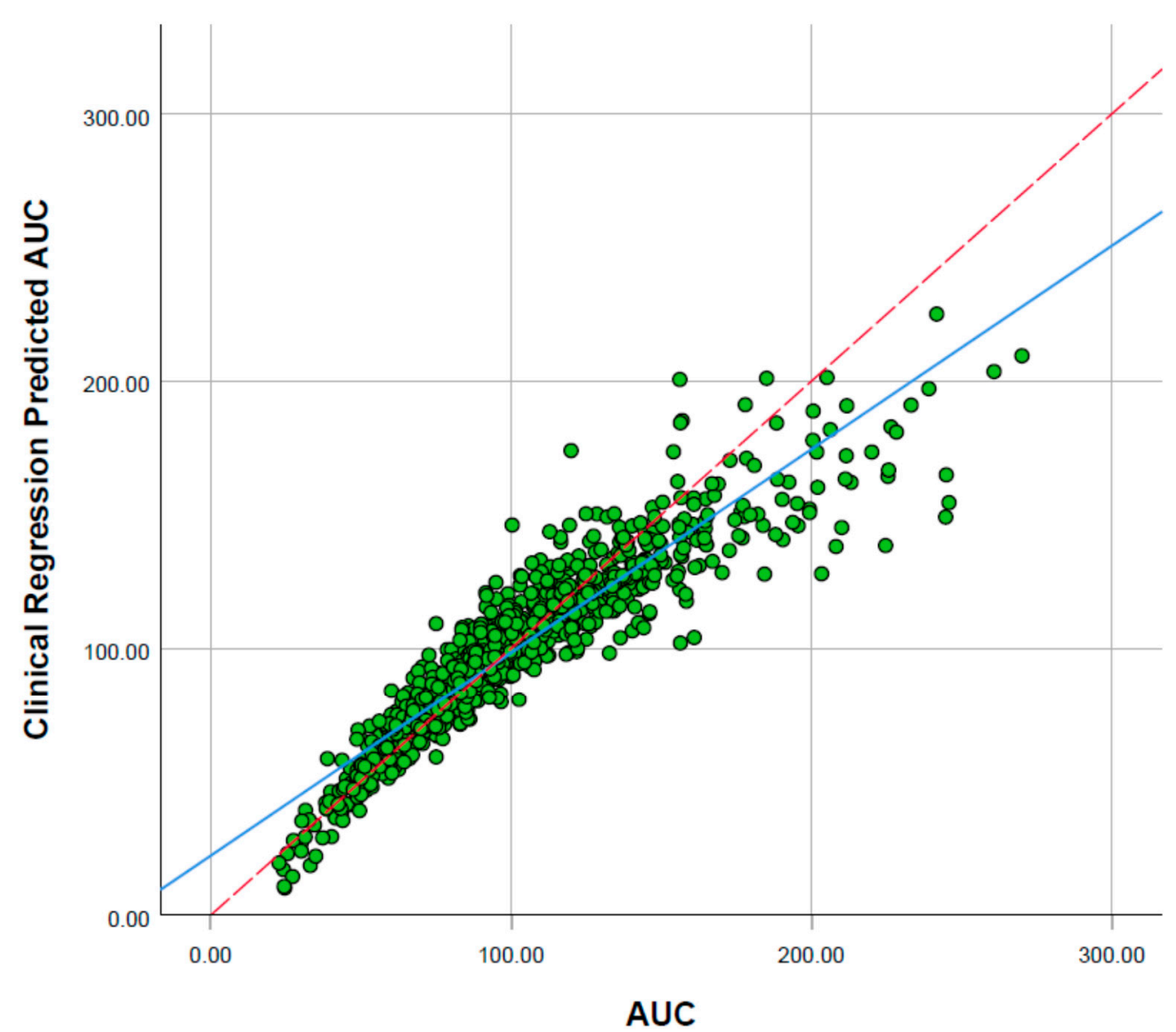

Figure 2. Correlation of model predicted steady-state sorafenib concentration predicted sorafenib AUC.

Table 1. Multivariable linear regression model performance characteristics.

\begin{tabular}{cccccc}
\hline Model & $\boldsymbol{R}^{\mathbf{2}}$ & $\begin{array}{c}\text { Std. Error of } \\
\text { the Estimate }\end{array}$ & $\boldsymbol{R}^{\mathbf{2}}$ Change & AUC ROC & $\begin{array}{c}\text { AUC ROC } \\
\text { Change }\end{array}$ \\
\hline $\mathbf{a}$ & 0.631 & 0.24141 & 0.631 & 0.953 & 0.953 \\
\hline $\mathbf{b}$ & 0.781 & 0.18614 & 0.150 & 0.981 & 0.028 \\
\hline $\mathbf{c}$ & 0.868 & 0.14458 & 0.087 & 0.990 & 0.009 \\
\hline $\mathbf{d}$ & 0.873 & 0.14156 & 0.006 & 0.991 & 0.001 \\
\hline $\mathbf{e}$ & 0.883 & 0.13619 & 0.010 & 0.991 & - \\
\hline $\mathbf{f}$ & 0.883 & 0.13595 & 0.001 & 0.991 & - \\
\hline
\end{tabular}

Model predictors (a) hepatic CYP3A4 abundance; (b) hepatic CYP3A4 abundance, albumin concentration; (c) hepatic CYP3A4 abundance, albumin concentration, BMI; (d) hepatic CYP3A4 abundance, albumin concentration, BMI, body surface area; (e) hepatic CYP3A4 abundance, albumin concentration, BMI, body surface area, sex; (f) hepatic CYP3A4 abundance, albumin concentration, BMI, body surface area, sex, weight; (g) hepatic CYP3A4 abundance, albumin concentration, BMI, body surface area, sex and weight.

Table 2. Classification matrixes describing the capability of linear regression models to identify individuals with a sub-therapeutic sorafenib steady state $C_{\max }$.

\begin{tabular}{|c|c|c|c|c|}
\hline & & \multicolumn{2}{|c|}{ Predicted Therapeutic $C_{\max }$} & \multirow{2}{*}{$\begin{array}{c}\text { Percentage } \\
\text { Correct }\end{array}$} \\
\hline & & Sub-Therapeutic & Therapeutic & \\
\hline \multirow{2}{*}{$\begin{array}{c}\text { Observed } \\
\text { Therapeutic } \mathrm{C}_{\max }\end{array}$} & Sub-therapeutic & $\begin{array}{c}60 \\
\text { (true negative) } \\
\end{array}$ & $\begin{array}{c}3 \\
\text { (false negative) }\end{array}$ & 95.2 \\
\hline & Therapeutic & $\begin{array}{c}47 \\
\text { (false positive) }\end{array}$ & $\begin{array}{c}890 \\
\text { (true positive) }\end{array}$ & 95.0 \\
\hline
\end{tabular}




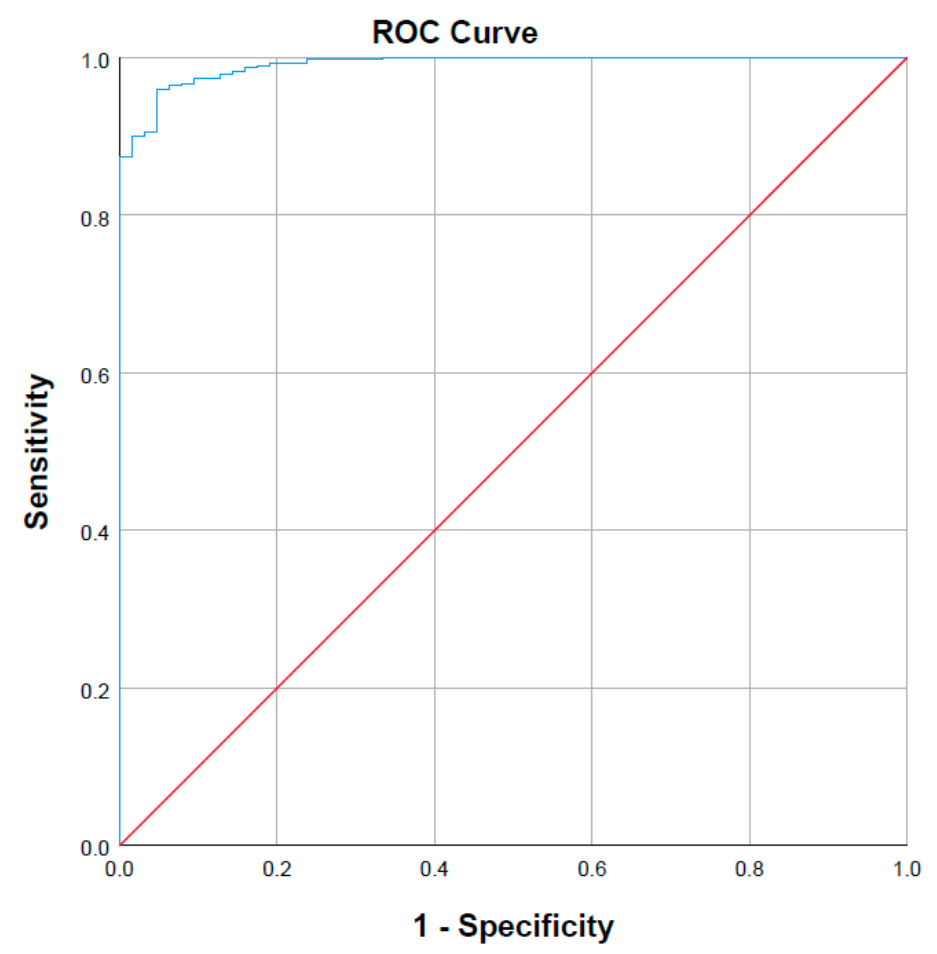

Figure 3. Receiver operating characteristic (ROC) curve demonstrating the prediction performance of a predicted steady state sorafenib AUC.

\subsection{Impact of Dose Individualisation}

The proportion of participants with a simulated sorafenib $\mathrm{C}_{\max }$ below, within and above the target 4.78 to $5.78 \mu \mathrm{g} / \mathrm{mL}$ range at Day 14 and Day 28 based on following flat $400 \mathrm{mg}$ dosing, concentration-guided dosing and concentration-guided dosing with MIDS is reported in Table 3. Concentration-guided sorafenib dosing without MIDS identified that $12.4 \%$ of subject $(62 / 500)$ failed to achieve a Day $14 C_{\max } \geq 4.78 \mu \mathrm{g} / \mathrm{mL}$ with $400 \mathrm{mg}$ twice daily dosing. Increasing the sorafenib dose to $600 \mathrm{mg}$ twice daily in individuals who failed to achieve a Day 14 sorafenib $C_{\max }>4.78 \mu \mathrm{g} / \mathrm{mL}$, while retaining the $400 \mathrm{mg}$ twice daily dose for those who did achieve a Day 14 sorafenib $C_{\max } \geq 4.78 \mu \mathrm{g} / \mathrm{mL}$ resulted in $99 \%$ of subjects (495/500) achieving a Day $28 C_{\max } \geq 4.78 \mu \mathrm{g} / \mathrm{mL}$. Concentration-guided sorafenib dosing without MIDS resulted in an additional 43 subjects achieving a Day 28 $\mathrm{C}_{\max }>5.78 \mu \mathrm{g} / \mathrm{mL}$ compared to flat $400 \mathrm{mg}$ dosing.

Table 3. Number of participant below, within and above target concentration range with different sorafenib dosing protocols.

\begin{tabular}{|c|c|c|c|c|c|c|}
\hline \multirow[b]{2}{*}{ Dosing Protocol } & \multicolumn{3}{|c|}{ Day 14} & \multicolumn{3}{|c|}{ Day 28} \\
\hline & $\begin{array}{l}<4.78 \\
\mu \mathrm{g} / \mathrm{mL}\end{array}$ & $\begin{array}{l}4.78 \text { to } 5.78 \\
\mu \mathrm{g} / \mathrm{mL}\end{array}$ & $\begin{array}{c}>5.78 \\
\mu \mathrm{g} / \mathrm{mL}\end{array}$ & $\begin{array}{l}<4.78 \\
\mu \mathrm{g} / \mathrm{mL}\end{array}$ & $\begin{array}{l}4.78 \text { to } 5.78 \\
\mu g / m L\end{array}$ & $\begin{array}{l}>5.78 \\
\mu \mathrm{g} / \mathrm{mL}\end{array}$ \\
\hline Flat dosing & 62 & 116 & 322 & 62 & 116 & 322 \\
\hline Concentration-guided dosing & 62 & 116 & 322 & 5 & 130 & 365 \\
\hline $\begin{array}{l}\text { Concentration-guided dosing } \\
\text { with MIDS }\end{array}$ & 34 & 135 & 331 & 5 & 164 & 336 \\
\hline
\end{tabular}

On the basis of MIDS, 52 subjects were allocated to receive an initial sorafenib dose of $500 \mathrm{mg}$ and 448 subjects were allocated to receive an initial sorafenib dose of $400 \mathrm{mg}$. Concentration-guided sorafenib dosing with MIDS resulted in 6.8\% (34/500) subjects failing to achieve a Day $14 \mathrm{C}_{\max } \geq 4.78 \mu \mathrm{g} / \mathrm{mL}$. Increasing the sorafenib dose to $600 \mathrm{mg}$ twice daily in individuals who failed to achieve a Day 14 sorafenib $C_{\max } \geq 4.78 \mu \mathrm{g} / \mathrm{mL}$, while retaining the MIDS informed twice daily dose for those who did achieve a Day 14 
sorafenib $C_{\max } \geq 4.78 \mu \mathrm{g} / \mathrm{mL}$ resulted in 99\% (495/500) of subjects achieving a Day 28 $\mathrm{C}_{\max } \geq 4.78 \mu \mathrm{g} / \mathrm{mL}$. Concentration-guided dosing with MIDS resulted in an additional 9 subjects achieving a Day $28 \mathrm{C}_{\max }>5.78 \mu \mathrm{g} / \mathrm{mL}$ compared to flat $400 \mathrm{mg}$ dosing. Post-hoc analysis demonstrated that three of these subjects would have a $C_{\max }<4.78 \mu \mathrm{g} / \mathrm{mL}$ with $400 \mathrm{mg}$ dosing, while the remaining six subjects could have retained a Day 28 $\mathrm{C}_{\max } \geq 4.78 \mu \mathrm{g} / \mathrm{mL}$ while avoiding a Day $28 \mathrm{C}_{\max }>5.78 \mu \mathrm{g} / \mathrm{mL}$ with a dose reduction from $500 \mathrm{mg}$ to $400 \mathrm{mg}$ following assessment of $C_{\max }$ on Day 14, however dose reduction was not incorporated into the simulation protocol.

\section{Discussion}

The present study demonstrated that concentration-guided dosing with MIDS facilitates therapeutic sorafenib exposure in $99 \%$ of subjects within 28 days while minimising the number of additional subjects at risk of supra-therapeutic dosing compared to concentration-guided dosing alone. Multivariable linear regression modelling demonstrated that variability in simulated sorafenib AUC and $C_{\max }$ is associated with hepatic CYP3A4 abundance, albumin concentration, BMI, sex, age and weight. Logistic regression modelling of these covariates predicted individuals likely to fail to achieve sorafenib $\mathrm{C}_{\max } \geq 4.78 \mathrm{mg} / \mathrm{L}$ with high sensitivity and specificity (95.2\% and $95 \%$, respectively). Incorporation of these parameters into an MIDS algorithm that allocated subjects to a $400 \mathrm{mg}$ or $500 \mathrm{mg}$ initial sorafenib dose resulted in a $50 \%$ reduction in the number of subjects that failed to achieve a Day $14 \mathrm{C}_{\max } \geq 4.78 \mathrm{mg} / \mathrm{L}$. When used in conjunction with concentration-guided dosing at Day 14 , this protocol resulted in $99 \%$ of subjects attaining a Day $28 \mathrm{C}_{\max } \geq 4.78 \mathrm{mg} / \mathrm{L}$.

The current study also highlights the potential danger of empiric concentration-guided dosing in terms of placing patients at an increased risk of toxicity. In the absence of MIDS, $69 \%$ of subjects $(43 / 62)$ that underwent a dose escalation from 400 to $600 \mathrm{mg}$ on Day 14 experienced a $C_{\max }$ on Day 28 that is associated with increased risk of grade II toxicity. Compared to concentration-guided dosing alone, the concentration-guided dosing with MIDS protocol reduced the number of additional subjects at increased risk of grade II toxicity on Day $28\left(\mathrm{C}_{\max } \geq 5.78 \mathrm{mg} / \mathrm{L}\right)$ from 43 to 9 .

PBPK modelling and simulation is an established tool to support drug discovery and development, and is a core element of the regulatory approval process in many jurisdictions [35]. Recent studies have further demonstrated the potential role of PBPK in predicting covariates affecting variability in drug exposure resulting from either patient characteristics or the drugs' physicochemical properties [24,25], giving rise to the intriguing potential for this platform to support model informed precision dosing [26,32]. Since the introduction of imatinib in 2001 there has been a growing evidence base supporting a role for concentration-guided KI dosing, despite this implementation of KI dose individualisation has remained challenging. Many early studies focussed on a potential role for TDM-guided KI dosing, however, sufficient evidence has yet to be generated to support widespread implementation for any KI. This has led to the exploration of novel approaches to facilitate precision KI dosing, which have included model informed precision dosing based on integrated simulation/prediction platforms such as PK-Sim ${ }^{\circledR}$, GastroPlus ${ }^{\mathrm{TM}}$, Phoenix ${ }^{\mathrm{TM}}$, and Simcyp ${ }^{\circledR}[26,36-38]$.

The target concentration range and dose escalation protocol used in the current study were based on the best current evidence $[11,16]$. The main limitation to this study remains the lack of independent verification of the 4.78 to $5.78 \mu \mathrm{g} / \mathrm{mL}$ target $C_{\max }$ range. Further, when considering the clinical implementation, it is also important to note that the rate at which sorafenib is absorbed from the GIT varies $>$ five-fold [6]. Variability in the rate of intestinal absorption results in marked variability in the time taken to reach $C_{\max }$ for sorafenib (1 to $6 \mathrm{~h}$ ). As such, in the absence of full PK (AUC) sampling, which is not practical in a clinical setting, concentration-guided sorafenib dosing based on a $C_{\max } \operatorname{target}$ is unlikely to be robust. 
Liver CYP3A4 abundance was identified as the dominant characteristic driving variability in sorafenib AUC and $\mathrm{C}_{\max }$. By accounting for this characteristic alone, it was possible to identifying subjects with a sub-therapeutic sorafenib $C_{\max }$ with a specificity of $74.6 \%$ and a sensitivity of $96.3 \%$. When hepatic CYP3A4 abundance was considered along with readily attained data regarding albumin concentration, BMI, BSA, sex and weight in combination with albumin concentration, these two parameters accounted for $>88 \%$ of multivariable model performance in terms of $R^{2}$, specificity and sensitivity (Table 1 ). These data suggest that consideration of liver CYP3A4 abundance may provide sufficient power to prospectively identify patients who are likely to require a higher sorafenib dose in order to achieve a therapeutic plasma concentration. Importantly, recent work in this [39] and other [40,41] laboratories has demonstrated that quantification of extracellular vesicle (EV)-derived CYP3A protein, mRNA and ex vivo activity robustly describes variability in CYP3A activity in humans.

This study identified the major physiological and molecular characteristics associated with between subject variability in sorafenib exposure to be hepatic CYP3A4 abundance, albumin concentration, BMI, BSA, sex and weight. Initial dose selection informed by a model accounting for these covariates resulted a quicker and more effective concentrationguided sorafenib dosing.

\section{Materials and Methods}

\subsection{Development and Verification of the Sorafenib PBPK Model Structural Model}

Sorafenib absorption was simulated using the advanced dissolution, absorption, and metabolism (ADAM) sub-model which incorporates membrane permeability, intestinal metabolism and transporter-mediated uptake and efflux. The ADAM sub-model was used in conjunction with a full-body PBPK model, containing compartments and drug distribution characteristics for all organs. All simulations were performed using Simcyp ${ }^{\circledR}$ (version 19.1, Certara, UK). The differential equations underpinning the model have been described previously [42].

\subsection{Development of the Sorafenib Compound Model}

The physicochemical, blood binding, absorption, distribution, elimination parameters utilised to construct the sorafenib compound model are summarised in Table 4 . Physicochemical properties were based on published literature and documents [43,44]. Metabolism and elimination parameters were incorporated based on reported intersystem extrapolation factor (ISEF) adjusted in vitro CYP and UDP-glucuronosyltransferase (UGT) data (Figure 4). 
Table 4. Model inputs used to build the sorafenib compound model.

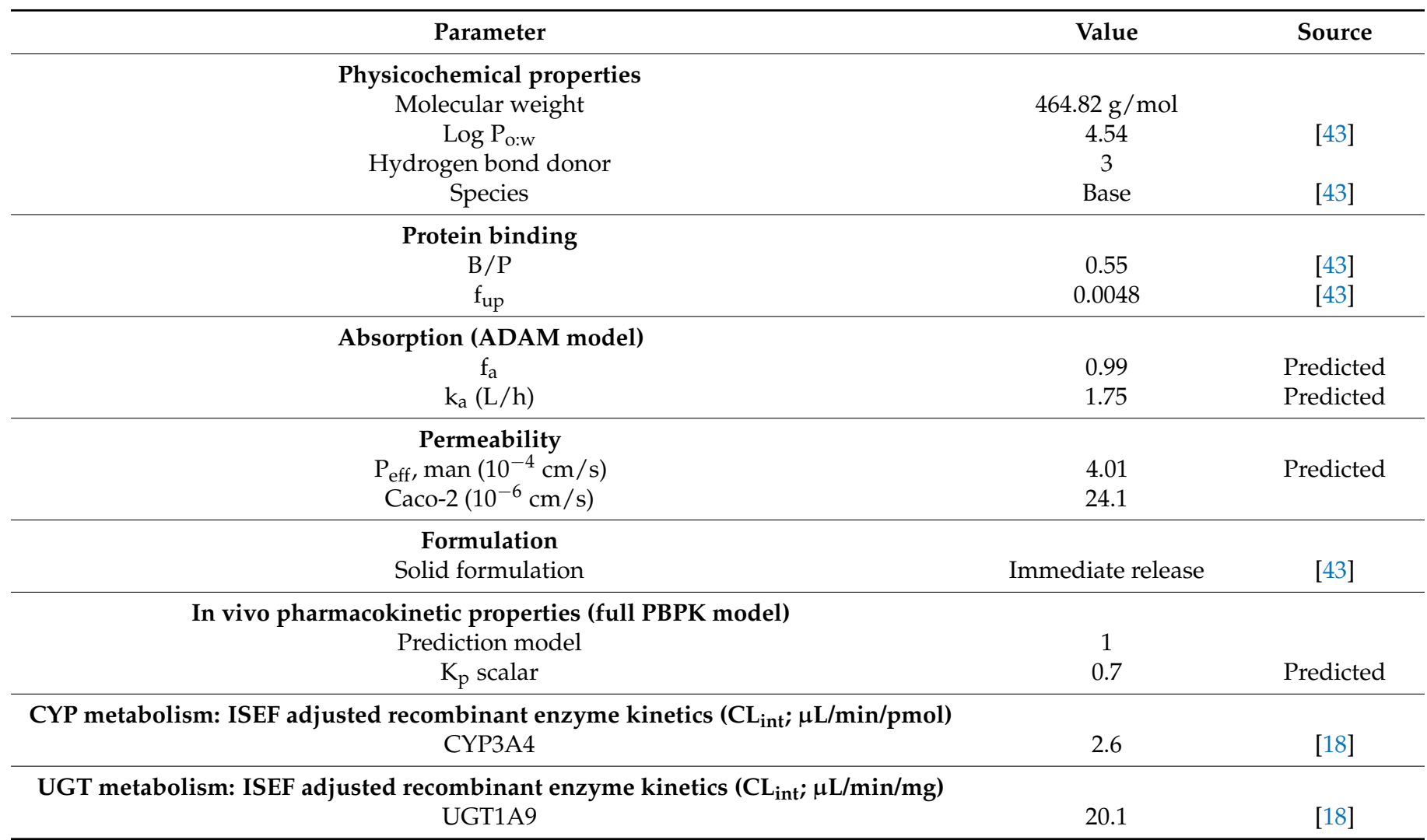

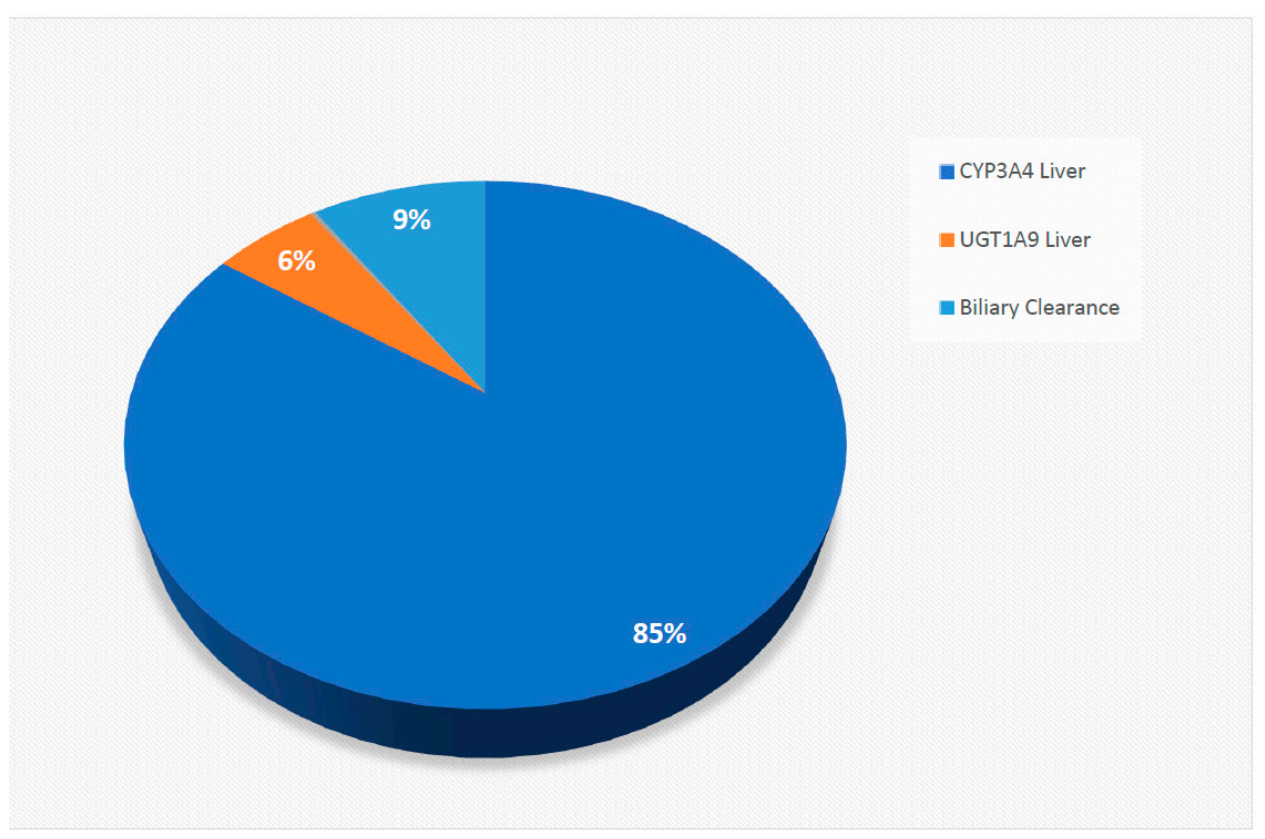

Figure 4. The pie chart demonstrated the relative contribution of CYP and UGT to simulated sorafenib elimination based on the predicted model.

\subsection{Population Model}

As no clinical trials evaluating sorafenib exposure have been performed in healthy volunteers, verification of the sorafenib compound model was performed using Sim-Cancer population cohort. Simulations performed to assess the physiological and molecular characteristics driving between-subject variability in sorafenib exposure at steady state also 
utilised the Sim-Cancer population cohort. The physiological and pathological characteristics of the Sim-cancer population have been determined based on a meta-analysis of cancer patients enrolled in clinical trials [45].

\subsection{Simulated Trial Designs}

During the model development stage, simulations included 10 trials with 10 subjects per trial (100 subjects total). During the verification stage, simulations were performed in 10 trials matched for sample size, dose, age range and sex distribution in the protocol described for the observed trial. Unless specified otherwise, parameters defining sorafenib exposure were assessed over $24 \mathrm{~h}$ following a single dose at 9:00 a.m. on day 1 .

\subsection{Validation of the Sorafenib Compound Model}

The sorafenib compound model was validated by comparing simulated AUC and $\mathrm{C}_{\max }$ values to reported observed values from matched clinical trials undertaken in cancer patients. A mean simulated parameter estimated within two-fold of the mean observed parameter and contained within the $90 \%$ confidence interval for the observed parameter was applied as the criteria to accept the model accuracy. The model goodness-of-fit was further verified by visual inspection of the overlay of mean simulated and observed sorafenib concentration-time profiles from individual clinical trials. Simulated $C_{\max }$ values were normalised to account for the mean fold error (MFE) between simulated and observed values determined from multiple dose validation studies when evaluating simulations against the observed target concentration range ( 4.78 to $5.78 \mu \mathrm{g} / \mathrm{mL})$.

\subsection{Physiological and Molecular Characteristics Driving Variability in Sorafenib Exposure}

The validated sorafenib compound model was used to evaluate associations between physiological and molecular covariates and steady-state sorafenib AUC and $C_{\max }$ [24]. A trial comprising 1000 subjects from the Sim-Cancer population was simulated over 15 days with $400 \mathrm{mg}$ of sorafenib administered orally in a fasted-state every $12 \mathrm{~h}$ for 14 days starting at 9:00 a.m. on Day 1. The steady state sorafenib AUC was determined over $12 \mathrm{~h}$ following the final dose of sorafenib at 9:00 p.m. on Day 14. The steady state sorafenib $\mathrm{C}_{\max }$ was determined as the maximum concentration following the final dose at 9:00 p.m. on Day 14.

Associations between physiological and molecular characteristics and sorafenib log transformed AUC and $\mathrm{C}_{\max }$ were evaluated by univariate and multivariate linear regression. Continuous variables were checked for normality and non-linearity of association, sex was coded as a binary variable. A multivariable linear regression model to predict the $\log$ transformed sorafenib $\mathrm{C}_{\max }$ was developed by stepwise forward inclusion of individually significant characteristics identified in the univariable regression analysis based on a probability of $F$ to enter $\leq 0.05$. The multivariable model (MIDS) predicted $C_{\max }$ was determined by back transformation of the model predicted $\log$ transformed $\mathrm{C}_{\max }$. The capacity of MIDS to identify subjects with a sub-therapeutic simulated sorafenib $C_{\max }$ determined by scaling the reported threshold for simulation accuracy was evaluated using classification matrix analysis and is summarised as model sensitivity and specificity. The predictive performance of MIDS was assessed by receiver operating characteristic curve (ROC) analysis. Statistical analysis was conducted using R version 4.0.2 and IBM SPSS Statistics for Windows version 23 (Release 2015, IBM, Armonk, NY, USA).

\subsection{Impact of Dose Individualisation}

A simulation was conducted to evaluate the capacity of concentration-guided sorafenib dose adjustment to achieve a steady state sorafenib $C_{\max }$ within the range 4.78 to $5.78 \mu \mathrm{g} / \mathrm{mL}$. Sorafenib exposure was simulated in a cohort of 500 subjects from the Sim-Cancer population (20 to 50 years old, $50 \%$ female) over 14 days with $400 \mathrm{mg}$ sorafenib administered orally in a fasted-state every $12 \mathrm{~h}$ starting at 9:00 a.m. on Day 1. Sorafenib $\mathrm{C}_{\max }$ was determined following the final dose at 9:00 p.m. on Day 14. Sorafenib exposure 
in subjects who failed to achieve a Day 14 normalised simulated $C_{\max } \geq 4.78 \mu \mathrm{g} / \mathrm{mL}$ was simulated over an additional 14 days with sorafenib administered at a dose of $600 \mathrm{mg}$ every $12 \mathrm{~h}$ starting at 9:00 a.m. on Day 15 . The post dose adjustment sorafenib $\mathrm{C}_{\max }$ was determined following the final dose at 9:00 p.m. on Day 28.

A simulation was conducted in the same cohort to evaluate the benefit of MIDS at baseline in conjunction with concentration-guided sorafenib dose adjustment. Demographic characteristics for the Sim-Cancer cohort were used to predict the normalised simulated Day 14 sorafenib $\mathrm{C}_{\max }$ based on the multivariable model described previously. Based on MIDS subjects with a predicted sorafenib $C_{\max } \geq 4.78 \mu \mathrm{g} / \mathrm{mL}$ received $400 \mathrm{mg}$ sorafenib twice daily, while subjects with predicted sorafenib $C_{\max }<4.78 \mu \mathrm{g} / \mathrm{mL}$ received $500 \mathrm{mg}$ sorafenib twice daily. Sorafenib exposure was simulated over 28 days as described for concentration-guided sorafenib dose adjustment without MIDS, with $\mathrm{C}_{\max }$ evaluated at Day 14 and Day 28 and a dose increase to $600 \mathrm{mg}$ between Day 15 and Day 28 for individuals who failed to achieve a Day $14 \mathrm{C}_{\max } \geq 4.78 \mu \mathrm{g} / \mathrm{mL}$.

Supplementary Materials: The following are available online at https:/ / www.mdpi.com/article/10 $.3390 /$ ph14050389/s1. Table S1: Verification of the impact of drug interactions on sorafenib exposure. Table S2: Summary of physiological and molecular characteristic considered in regression analyses. Table S3: Logistic regression analysis of therapeutic $C_{\max }$ threshold of $>5.5926 \mathrm{mg} / \mathrm{L}$.

Author Contributions: Conceptualisation, W.R., M.J.S., A.M.H. and A.R.; methodology, W.R., M.J.S., A.M.H. and A.R.; software, A.R.; validation, A.R. and W.R.; formal analysis, W.R. and A.R.; investigation, W.R. and A.R.; resource, A.R.; data curation, W.R. and A.R.; writing-original draft preparation, W.R..; writing-review and editing, W.R., A.R., A.M.H. and M.J.S.; visualisation, W.R. and A.R.; supervision, M.J.S., A.M.H. and A.R.; project administration, M.J.S., A.M.H. and A.R.; funding acquisition, A.R. All authors have read and agreed to the published version of the manuscript.

Funding: WR is supported by a Royal Thai Government Scholarship. A.R. and M.J.S. are supported by Cancer Council Beat Cancer Fellowships. A.M.H. is supported by a National Breast Cancer Foundation Fellowship.

Institutional Review Board Statement: Not applicable.

Informed Consent Statement: Not applicable.

Data Availability Statement: The data that support the findings of this study are available from the corresponding author upon reasonable request.

Conflicts of Interest: A.R. and M.J.S. report investigator-initiated project grants from Pfizer, outside the scope of the submitted work. W.R. and A.M.H. have no conflicts of interest to disclose.

\section{References}

1. Vogel, A.; Cervantes, A.; Chau, I.; Daniele, B.; Llovet, J.M.; Meyer, T.; Nault, J.C.; Neumann, U.; Ricke, J.; Sangro, B.; et al. Hepatocellular carcinoma: ESMO Clinical Practice Guidelines for diagnosis, treatment and follow-up. Ann Oncol. 2018, 29 (Suppl. 4), 238-255. [CrossRef]

2. Wang, H.-T.; Xia, M. A meta-analysis of efficacy and safety of sorafenib versus other targeted agents for metastatic renal cell carcinoma. Medicine 2019, 98, e13779. [CrossRef]

3. Strumberg, D.; Clark, J.W.; Awada, A.; Moore, M.J.; Richly, H.; Hendlisz, A.; Hirte, H.W.; Eder, J.P.; Lenz, H.-J.; Schwartz, B. Safety, Pharmacokinetics, and Preliminary Antitumor Activity of Sorafenib: A Review of Four Phase I Trials in Patients with Advanced Refractory Solid Tumors. Oncologist 2007, 12, 426-437. [CrossRef] [PubMed]

4. Awada, A.; Hendlisz, A.; Gil, T.; Bartholomeus, S.; Mano, M.; de Valeriola, D.; Strumberg, D.; Brendel, E.; Haase, C.G.; Schwartz, B.; et al. Phase I safety and pharmacokinetics of BAY 43-9006 administered for 21 days on/7 days off in patients with advanced, refractory solid tumours. Br. J. Cancer 2005, 92, 1855-1861. [CrossRef]

5. Moore, M.; Hirte, H.W.; Siu, L.; Oza, A.; Hotte, S.J.; Petrenciuc, O.; Cihon, F.; Lathia, C.; Schwartz, B. Phase I study to determine the safety and pharmacokinetics of the novel Raf kinase and VEGFR inhibitor BAY 43-9006, administered for 28 days on/7 days off in patients with advanced, refractory solid tumors. Ann. Oncol. 2005, 16, 1688-1694. [CrossRef]

6. Jain, L.; Woo, S.; Gardner, E.R.; Dahut, W.L.; Kohn, E.C.; Kummar, S.; Mould, D.R.; Giaccone, G.; Yarchoan, R.; Venitz, J.; et al. Population pharmacokinetic analysis of sorafenib in patients with solid tumours. Br. J. Clin. Pharmacol. 2011, 72, 294-305. [CrossRef] 
7. Sharma, M.; Holmes, H.M.; Mehta, H.B.; Chen, H.; Aparasu, R.R.; Shih, Y.-C.T.; Giordano, S.H.; Johnson, M.L. The concomitant use of tyrosine kinase inhibitors and proton pump inhibitors: Prevalence, predictors, and impact on survival and discontinuation of therapy in older adults with cancer. Cancer 2019, 125, 1155-1162. [CrossRef] [PubMed]

8. Ruanglertboon, W.; Sorich, M.J.; Logan, J.M.; Rowland, A.; Hopkins, A.M. The effect of proton pump inhibitors on survival outcomes in advanced hepatocellular carcinoma treated with sorafenib. J. Cancer Res. Clin. Oncol. 2020, 146, 2693-2697. [CrossRef] [PubMed]

9. Lalani, A.A.; McKay, R.R.; Lin, X.; Simantov, R.; Kaymakcalan, M.D.; Choueiri, T.K. Proton Pump Inhibitors and Survival Outcomes in Patients With Metastatic Renal Cell Carcinoma. Clin. Genitourin. Cancer 2017, 15, 724-732. [CrossRef] [PubMed]

10. Au, T.H.; Bailey, E.B.; Patel, S.B.; Tantravahi, S.K.; Agarwal, N.; Stenehjem, D.D. Effect of concomitant proton pump inhibitor (PPI) on effectiveness of tyrosine kinase inhibitor (TKI) in patients with metastatic renal cell carcinoma (mRCC). J. Clin. Oncol. 2016, 34 (Suppl. 2), 608. [CrossRef]

11. Fukudo, M.; Ito, T.; Mizuno, T.; Shinsako, K.; Hatano, E.; Uemoto, S.; Kamba, T.; Yamasaki, T.; Ogawa, O.; Seno, H.; et al. Exposure-toxicity relationship of sorafenib in Japanese patients with renal cell carcinoma and hepatocellular carcinoma. Clin. Pharmacokinet. 2014, 53, 185-196. [CrossRef] [PubMed]

12. Ruanglertboon, W.; Sorich, M.J.; Rowland, A.; Hopkins, A.M. Effect of early adverse events resulting in sorafenib dose adjustments on survival outcomes of advanced hepatocellular carcinoma patients. Int. J. Clin. Oncol. 2020, 25, 1672-1677. [CrossRef] [PubMed]

13. de Wit, D.; Guchelaar, H.J.; den Hartigh, J.; Gelderblom, H.; van Erp, N.P. Individualized dosing of tyrosine kinase inhibitors: Are we there yet? Drug Discov. Today 2015, 20, 18-36. [CrossRef] [PubMed]

14. Mueller-Schoell, A.; Groenland, S.L.; Scherf-Clavel, O.; van Dyk, M.; Huisinga, W.; Michelet, R.; Jaehde, U.; Steeghs, N.; Huitema, A.D.R.; Kloft, C. Therapeutic drug monitoring of oral targeted antineoplastic drugs. Eur. J. Clin. Pharmacol. 2020, 29 , iv238-iv255. [CrossRef]

15. Semrad, T.J.; Gandara, D.R.; Lara, P.N., Jr. Enhancing the clinical activity of sorafenib through dose escalation: Rationale and current experience. Ther. Adv. Med. Oncol. 2011, 3, 95-100. [CrossRef]

16. Escudier, B.; Szczylik, C.; Hutson, T.E.; Demkow, T.; Staehler, M.; Rolland, F.; Negrier, S.; Laferriere, N.; Scheuring, U.J.; Cella, D.; et al. Randomized phase II trial of first-line treatment with sorafenib versus interferon Alfa-2a in patients with metastatic renal cell carcinoma. J. Clin. Oncol. 2009, 27, 1280-1289. [CrossRef] [PubMed]

17. Verheijen, R.B.; Yu, H.; Schellens, J.H.M.; Beijnen, J.H.; Steeghs, N.; Huitema, A.D.R. Practical Recommendations for Therapeutic Drug Monitoring of Kinase Inhibitors in Oncology. Clin. Pharmacol. Ther. 2017, 102, 765-776. [CrossRef]

18. Rowland, A.; van Dyk, M.; Mangoni, A.A.; Miners, J.O.; McKinnon, R.A.; Wiese, M.D.; Rowland, A.; Kichenadasse, G.; Gurney, H.; Sorich, M.J. Kinase inhibitor pharmacokinetics: Comprehensive summary and roadmap for addressing inter-individual variability in exposure. Expert Opin. Drug Metab. Toxicol. 2017, 13, 31-49. [CrossRef] [PubMed]

19. Darwich, A.; Ogungbenro, K.; Hatley, O.; Rostami-Hodjegan, A. Role of pharmacokinetic modeling and simulation in precision dosing of anticancer drugs. Transl. Cancer Res. 2017. [CrossRef]

20. Hopkins, A.M.; Menz, B.D.; Wiese, M.D.; Kichenadasse, G.; Gurney, H.; McKinnon, R.A.; Rowland, A.; Sorich, M.J. Nuances to precision dosing strategies of targeted cancer medicines. Pharmacol. Res. Perspect. 2020, 8, e00625. [CrossRef]

21. Kang, J.S.; Lee, M.H. Overview of therapeutic drug monitoring. Korean J. Intern. Med. 2009, 24, 1-10. [CrossRef] [PubMed]

22. Thomson, A. TDM-A Multidisciplinary Approach. Ther. Drug Monit. 1997, 19, 490. [CrossRef]

23. Sánchez-Hernández, J.G.; Rebollo, N.; Martin-Suarez, A.; Calvo, M.V.; Muñoz, F. A 3-year prospective study of a multidisciplinary early proactive therapeutic drug monitoring programme of infliximab treatments in inflammatory bowel disease. Br. J. Clin. Pharmacol. 2020, 86, 1165-1175. [CrossRef] [PubMed]

24. Sorich, M.J.; Mutlib, F.; van Dyk, M.; Hopkins, A.M.; Polasek, T.M.; Marshall, J.C.; Rodrigues, A.D.; Rowland, A. Use of Physiologically Based Pharmacokinetic Modeling to Identify Physiological and Molecular Characteristics Driving Variability in Axitinib Exposure: A Fresh Approach to Precision Dosing in Oncology. J. Clin. Pharmacol. 2019, 59, 872-879. [CrossRef] [PubMed]

25. Rowland, A.; van Dyk, M.; Hopkins, A.M.; Mounzer, R.; Polasek, T.M.; Rostami-Hodjegan, A.; Sorich, M.J. Physiologically Based Pharmacokinetic Modeling to Identify Physiological and Molecular Characteristics Driving Variability in Drug Exposure. Clin. Pharmacol. Ther. 2018, 104, 1219-1228. [CrossRef] [PubMed]

26. Polasek, T.M.; Rostami-Hodjegan, A. Virtual Twins: Understanding the Data Required for Model-Informed Precision Dosing. Clin. Pharmacol. Ther. 2020, 107, 742-745. [CrossRef]

27. Kluwe, F.; Michelet, R.; Mueller-Schoell, A.; Maier, C.; Klopp-Schulze, L.; van Dyk, M.; Mikus, G.; Huisinga, W.; Kloft, C. Perspectives on Model-Informed Precision Dosing in the Digital Health Era: Challenges, Opportunities, and Recommendations. Clin. Pharmacol. Ther. 2020, 109, 29-36. [CrossRef]

28. Polasek, T.M.; Polak, S.; Doogue, M.P.; Rostami-Hodjegan, A.; Miners, J.O. Assessment of inter-individual variability in predicted phenytoin clearance. Eur. J. Clin. Pharmacol. 2009, 65, 1203-1210. [CrossRef]

29. Chetty, M.; Cain, T.; Wedagedera, J.; Rostami-Hodjegan, A.; Jamei, M. Application of Physiologically Based Pharmacokinetic (PBPK) Modeling Within a Bayesian Framework to Identify Poor Metabolizers of Efavirenz (PM), Using a Test Dose of Efavirenz. Front. Pharmacol. 2018, 9, 247. [CrossRef]

30. Tsamandouras, N.; Rostami-Hodjegan, A.; Aarons, L. Combining the 'bottom up' and 'top down' approaches in pharmacokinetic modelling: Fitting PBPK models to observed clinical data. Br. J. Clin. Pharmacol. 2015, 79, 48-55. [CrossRef] 
31. Tylutki, Z.; Polak, S.; Wiśniowska, B. Top-down, Bottom-up and Middle-out Strategies for Drug Cardiac Safety Assessment via Modeling and Simulations. Curr. Pharmacol. Rep. 2016, 2, 171-177. [CrossRef]

32. Polasek, T.M.; Tucker, G.T.; Sorich, M.J.; Wiese, M.D.; Mohan, T.; Rostami-Hodjegan, A.; Korprasertthaworn, P.; Perera, V.; Rowland, A. Prediction of olanzapine exposure in individual patients using physiologically based pharmacokinetic modelling and simulation. Br. J. Clin. Pharmacol. 2018, 84, 462-476. [CrossRef]

33. Van Dyk, M.; Rowland, A. PBPK modeling as an approach to evaluate the effect of covariates and drug-drug interactions on variability in EGFR kinase inhibitor exposure. Transl. Cancer Res. 2017, 6, S1600-S1615. [CrossRef]

34. Minami, H.; Kawada, K.; Ebi, H.; Kitagawa, K.; Kim, Y.-I.; Araki, K.; Mukai, H.; Tahara, M.; Nakajima, H.; Nakajima, K. Phase I and pharmacokinetic study of sorafenib, an oral multikinase inhibitor, in Japanese patients with advanced refractory solid tumors. Cancer Sci. 2008, 99, 1492-1498. [CrossRef] [PubMed]

35. Shebley, M.; Sandhu, P.; Riedmaier, A.E.; Jamei, M.; Narayanan, R.; Patel, A.; Peters, S.A.; Reddy, V.P.; Zheng, M.; de Zwart, L.; et al. Physiologically Based Pharmacokinetic Model Qualification and Reporting Procedures for Regulatory Submissions: A Consortium Perspective. Clin. Pharmacol. Ther. 2018, 104, 88-110. [CrossRef]

36. Basu, S.; Lien, Y.T.; Vozmediano, V.; Schlender, J.-F.; Eissing, T.; Schmidt, S.; Niederalt, C. Physiologically Based Pharmacokinetic Modeling of Monoclonal Antibodies in Pediatric Populations Using PK-Sim. Front. Pharmacol. 2020, 11, 868. [CrossRef] [PubMed]

37. Hennig, S.; Holthouse, F.; Staatz, C.E. Comparing dosage adjustment methods for once-daily tobramycin in paediatric and adolescent patients with cystic fibrosis. Clin. Pharmacokinet. 2015, 54, 409-421. [CrossRef] [PubMed]

38. Song, L.; He, C.-Y.; Yin, N.-G.; Liu, F.; Jia, Y.-T.; Liu, Y. A population pharmacokinetic model for individualised dosage regimens of vancomycin in Chinese neonates and young infants. Oncotarget 2017, 8, 105211-105221. [CrossRef]

39. Rowland, A.; Ruanglertboon, W.; van Dyk, M.; Wijayakumara, D.; Wood, L.; Meech, R.; Mackenzie, P.; Rodrigues, A.; Marshall, J.; Sorich, M. Plasma Extracellular Nanovesicle (Exosome) derived biomarkers for ADME pathways: A novel approach to characterise variability in drug exposure. Br. J. Clin. Pharmacol. 2019, 85, 216-226. [CrossRef]

40. Kumar, S.; Sinha, N.; Gerth, K.A.; Rahman, M.A.; Yallapu, M.M.; Midde, N.M. Specific packaging and circulation of cytochromes P450, especially 2E1 isozyme, in human plasma exosomes and their implications in cellular communications. Biochem. Biophys. Res. Commun. 2017, 491, 675-680. [CrossRef]

41. Achour, B.; Al-Majdoub, Z.M.; Grybos-Gajniak, A.; Lea, K.; Kilford, P.; Zhang, M.; Knight, D.; Barber, J.; Schageman, J.; RostamiHodjegan, A. Liquid Biopsy Enables Quantification of the Abundance and Interindividual Variability of Hepatic Enzymes and Transporters. Clin. Pharmacol. Ther. 2021, 109, 222. [CrossRef] [PubMed]

42. Rowland Yeo, K.; Jamei, M.; Yang, J.; Tucker, G.T.; Rostami-Hodjegan, A. Physiologically based mechanistic modelling to predict complex drug-drug interactions involving simultaneous competitive and time-dependent enzyme inhibition by parent compound and its metabolite in both liver and gut-the effect of diltiazem on the time-course of exposure to triazolam. Eur. J. Pharm. Sci. 2010, 39, 298-309. [PubMed]

43. European Medicines Agency. Nexavar: European Public Assessment Reports (EPAR)-Scientific Discussion. 3 March 2007. Available online: http:/ / www.ema.europa.eu/docs/en_GB/document_library/EPAR-Scientific_Discussion/human/000690 /WC500027707.pdf (accessed on 20 February 2021).

44. Liu, B.; Crewe, H.K.; Ozdemir, M.; Yeo, K.R.; Tucker, G.; Rostami-Hodjegan, A. The absorption kinetics of ketoconazole plays a major role in explaining the reported variability in the level of interaction with midazolam: Interplay between formulation and inhibition of gut wall and liver metabolism. Biopharm. Drug Dispos. 2017, 38, 260-270. [CrossRef] [PubMed]

45. Schwenger, E.; Reddy, V.P.; Moorthy, G.; Sharma, P.; Tomkinson, H.; Masson, E.; Vishwanathan, K. Harnessing Meta-analysis to Refine an Oncology Patient Population for Physiology-Based Pharmacokinetic Modeling of Drugs. Clin. Pharmacol. Ther. 2018, 103, 271-280. [CrossRef] 